\title{
The dark side of the moon: severe therapy-resistant asthma in children
}

\author{
F.M. de Benedictis 1 , I. Carloni1 ${ }^{1}$, A. Bush
}

ABSTRACT: The dark side of the moon: severe therapyresistant asthma in children. F.M. de Benedictis, I. Carloni, A. Bush.

Problematic severe asthma is the term used to describe children whose asthma is not responsive to standard therapy with high-dose inhaled corticosteroids and additional controllers. These children need to be assessed by a step-wise systematic protocol in order to confirm the diagnosis, evaluate co-morbidities, assess the adherence to treatment, and finally evaluate the basic management. More than half of these children have "difficult-to-treat asthma", which improves if the basic management is correct. Children whose asthma remains uncontrolled despite resolution of any reversible factors are termed "severe therapy-resistant" asthmatics; for them, an individualised treatment plan is developed after a detailed and invasive protocol of investigation. Therapeutic options for these patients can be divided into medications used in lower doses for children with less severe asthma, and those used in other pediatric diseases but not for asthma. Most treatments are unlicensed and there is a lack of high-quality evidence. Children with recurrent severe exacerbations, in particular in the context of good baseline asthma control, are particularly difficult to treat, and there is no evidence on which therapeutic option to recommend. International collaborations, using standard protocols of investigation, are needed to better understand mechanisms of severe therapy-resistant asthma and to deliver evidence-based treatments in the future.

Monaldi Arch Chest Dis 2012; 77: 2, 83-93.

Keywords: Asthma, Airway inflammation, Steroid resistance.

${ }^{1}$ Department of Mother and Child Health, Salesi Children's Hospital, Ancona, Italy.

2 Department of Paediatric Respiratory Medicine, Imperial College and Royal Brompton Hospital, London, UK.

Correspondence: Fernando Maria de Benedictis, MD; Division of Pediatrics, Salesi Children's Hospital, 11, Via Corridoni, 60123 Ancona, Italy; e-mail: debenedictis@ospedaliriuniti.marche.it

.. and if the band you're in starts playing different tunes (PINK FLOYD)

\section{Introduction}

"Problematic severe asthma" is an umbrella term which encompasses the description of children referred to specialist care with asthma not responding to standard therapy [1]. Although the majority of children with asthma respond well to low-dose inhaled corticosteroids (ICS) administered regularly with an age-appropriate device, a significant proportion still have problematic, severe disease that is not controlled with high-dose ICS and additional controller therapies, such as long-acting beta-agonist (LABA), leukotriene receptor antagonist (LTRA) and low-dose theophylline. The exact number of patients with problematic severe asthma is hard to determine, but it is probably less than $5 \%$ of all children with asthma. These children usually present with chronic symptoms of poor baseline control and/or acute exacerbations, despite the prescription of multiple drug therapies.

Patients with problematic severe asthma warrant age-appropriate assessment using a step-wise approach, in order to be placed in one of four categories [2]:

- " not asthma at all" (wrong diagnosis);
- "asthma plus" (presence of important co-morbidities);

- "difficult-to-treat asthma" (asthma which improves if the basic management - i.e. adherence to treatment, allergen and other adverse exposures, psychological issues - is properly modified);

- "severe therapy-resistant asthma" (asthma which remains uncontrolled even after the resolution of any reversible factor and optimization of the basic management).

The latter category of patients merits assessment with a detailed and invasive protocol of investigation in order to verify the pattern of inflammation, any degree of steroid responsiveness, the presence of persistent airflow limitation and the concordance between symptoms and airway inflammation, before an individualised treatment plan is assigned [3].

A significant unmet clinical need remains in this group of patients, specifically a requirement for therapies which reduce systemic steroid exposure [4]. Most treatments are not licensed, except for omalizumab. Treatment options to be considered for truly severe therapy-resistant asthmatic children do not stand upon high quality randomised trials, and the level of evidence is still poor. Data is mainly extrapolated from adults with severe asthma and children with mild to moderate asthma not controlled on ICS. Medications can be 
divided into drugs used in lower doses for children with less severe asthma (conventional medications) and those used in other paediatric diseases but usually not in asthma (experimental therapies).

The aim of this article is to review the scientific evidence on the therapeutic options in children with severe therapy-resistant asthma with a particular focus on what is new since our previous report [5].

\section{Conventional asthma medications}

Several therapeutic options may be considered for a child with truly severe, therapy-resistant asthma. A summary flow chart of recommendations for treatment is given in figure 1.
High-dose conventional inhaled corticosteroids

There is marked variation across Europe in the definition of high-dose ICS in childhood. Highdose ICS has been arbitrarily defined as either 500 $\mathrm{mcg} /$ day fluticasone propionate equivalent, or 800 $\mathrm{mcg} /$ day beclomethasone dipropionate [5]. The level of the plateau of the dose-response curve to ICS in asthmatic children is a matter of debate [6]. Despite the fact that in many it can be as low as $200 \mathrm{mcg} /$ day fluticasone [7], there is reason to believe that in some children higher than conventional doses of ICS ( $>800 \mathrm{mcg} /$ day beclomethasone equivalent) may be beneficial and even safe. First, steroid resistance is a spectrum rather than an all-or-nothing phenomenon, and relative steroid

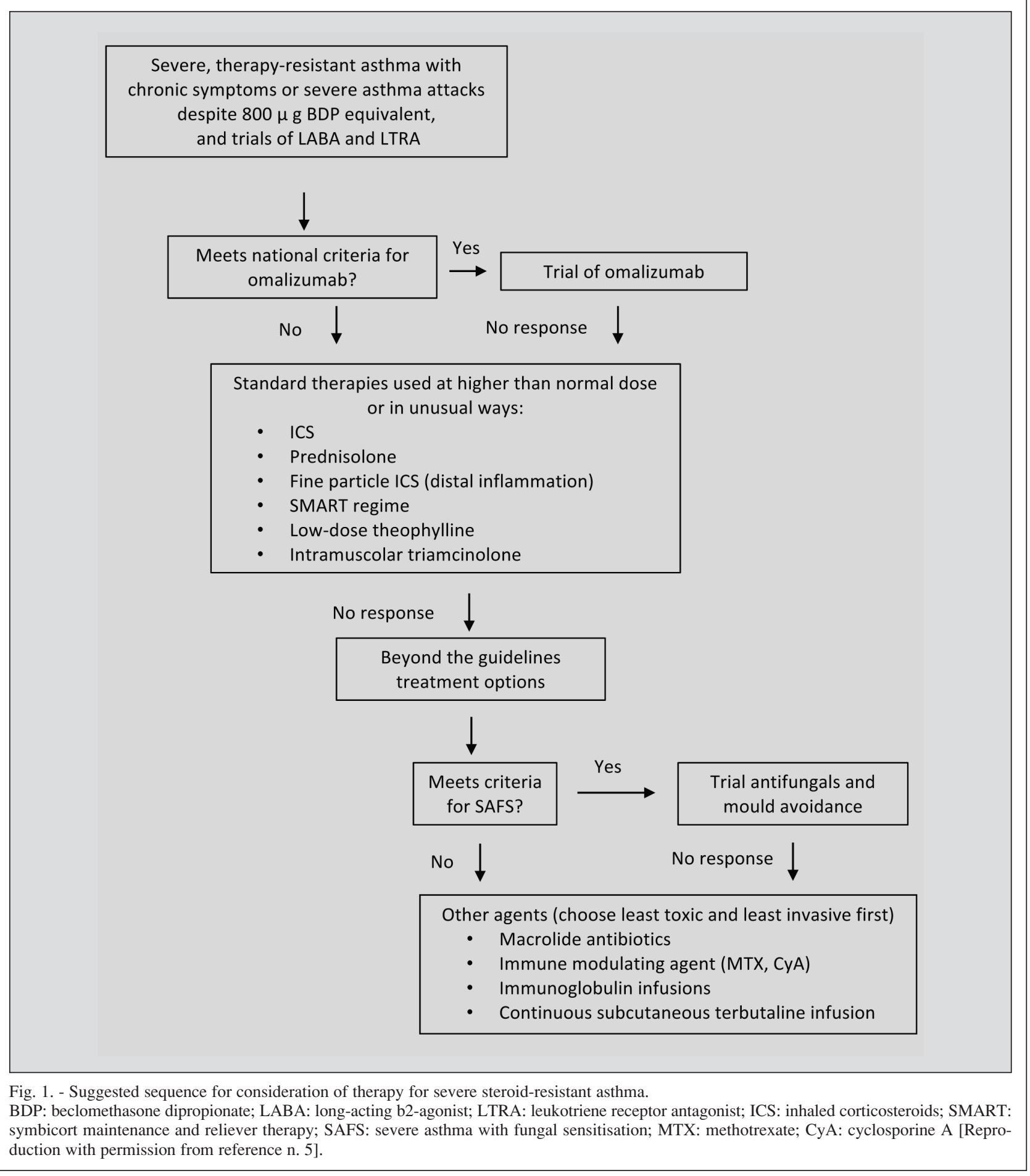


insensitivity may be overcome by higher doses [8]. Secondly, studies in adults demonstrate that high doses of ICS may be less well absorbed from the airway, thus suggesting that these doses of ICS, appropriate to degree of airway inflammation, may be safer than is thought [9].

There are few studies on high-dose ICS in severe asthma in children [10]. The evidence that higher than conventional ICS doses allows children on oral corticosteroids (OCS) to reduce the dose is anecdotal. Although firm recommendations cannot be made, in a severe asthmatic child on OCS it would nevertheless seem reasonable to try to reduce the oral intake by increasing ICS to higher than conventional doses (perhaps to as high as $2000 \mathrm{mcg}$ beclomethasone equivalent per day). In case of benefit, ICS should be tapered to the lowest effective dose; in case of no response, ICS should be reduced to the daily dose prescribed prior to the increase. In any case, the use of high-dose ICS should only occur under the careful supervision of a specialist, in order to closely monitor potential side effects.

\section{Oral corticosteroids}

This therapy is usually considered the next step for treatment of children whose asthma has not been controlled by a combination of ICS, LABA and LTRA. There is insufficient evidence in the literature to recommend the starting dose, the frequency of administration (daily or alternate day), the trial duration, and how quickly to taper OCS once control has been achieved. A reasonable starting dose might be $0,5 \mathrm{mg} / \mathrm{Kg}$ daily of prednisolone administered for 2 weeks. If there is no significant benefit, medication should be stopped quickly; if there is a response, the dose should be slowly tapered to the lowest dose able to control symptoms. In this context, alternate day treatment should be initiated as soon as possible. OCS treatment, irrespective of continuous or intermittent administration, is associated with an increased risk of adrenal insufficiency, growth retardation, cataract and bone fractures [11, 12]. On this background, it is mandatory that children on regular OCS therapy are strictly monitored by specialists for potentially severe side effects [13].

\section{Anti-immunoglobulin E antibody}

Omalizumab (Xolair®; Genentech, San Francisco, CA, USA), a humanized monoclonal antibody against immunoglobulin (Ig)-E, has been successfully administered as an add-on therapy in children with severe therapy-resistant asthma who meet the following criteria: $i$ ) ongoing chronic symptoms or severe exacerbations despite highdose medication, or adequate control of asthma only at the cost unacceptable side-effects; ii) known IgE-mediated sensitisation to one or more aero-allergens; and iii) every reasonable effort has been made to reduce the environmental allergen burden. The upper limit of total serum IgE recommended for therapy in children has just been raised to 1,500 I.U. Despite this, substantial numbers of children will have higher levels, and whether they will benefit from therapy is still unknown.
In long-term trials in school-age children and adolescents with moderate-to-severe asthma, omalizumab administered subcutaneously was effective in significantly reducing the ICS dose and the number of exacerbations, and improving asthma symptoms and the quality of life [14-18]. Omalizumab was safe and well tolerated [16-18], but the long-term safety and efficacy of the drug has yet to be determined [19]. A recent 6-year pragmatic review showed that asthma control improved with omalizumab over time [20], thus supporting the usefulness of adding omalizumab to long-term management of patients with severe therapy-resistant asthma [21, 22]. In keeping with the known effect on airway eosinophilia in adults [23], a fall in exhaled nitric oxide fraction (FENO) was observed in a paediatric study [24]. In a post hoc analysis of patients who had an increased blood eosinophil count $(>2 \%)$ and an increased level of exhaled nitric oxide (>20 ppb), those receiving omalizumab had rates of reduction in exacerbations that were significantly greater than those in patients who were treated according to standard guidelines [25]. Additional research is needed to determine whether such markers constitute a true response phenotype for omalizumab therapy [26].

Omalizumab should be tried in children who have poor asthma control and/or exacerbations in spite of daily or alternate day OCS treatment or therapy with high-dose ICS or with ICS plus LABA and/or LTRA. Currently, there are no tests which can currently be recommended in order to predict who will respond to omalizumab. Omalizumab has the inconvenience of subcutaneous administration, the need for observation of the patient after each injection for risk of anaphylaxis $(0,1 \%)$, and elevated costs. Cost-benefit analysis suggests a fiscal saving if omalizumab is given to children with five or more admissions, cumulatively 20 days or more in hospital per year [27]. In children fulfilling the criteria, omalizumab should always precede trials with other steroid sparing agents.

\section{Treatment of distal airway inflammation}

Early studies with transbronchial biopsy found that distal airway inflammation was a distinctive feature of some adult asthmatics, especially those with nocturnal asthma [28-30]. Due to the risk of transbronchial biopsy in children it cannot be performed in this context, but distal airway inflammation may be investigated by partitioning FENO into proximal $\left(\mathrm{J}_{\mathrm{NO}}\right)$ and distal $\left(\mathrm{C}_{\mathrm{ALV}}\right)$ fractions by measuring FENO production at multiple flow rates $[31,32]$.

The relationship between FENO and eosinophilic inflammation is particularly loose in children with severe therapy-resistant asthma on high-dose ICS or OCS [33-35]. It is not clear whether distal inflammation is an intrinsic part of severe therapy-resistant asthma or reflects poor distal airway deposition of conventional ICS. There are two possible approaches to targeting the distal airways, either using OCS and relying on airway perfusion, or using small particle ICS such as $\mathrm{Q}_{\mathrm{VAR}}{ }^{\mathrm{TM}}$ or ciclesonide $[36,37]$ to 
ameliorate distal airway deposition. Even though the role of distal airway inflammation is still contentious, in a child with severe therapy-resistant asthma, who has evidence of distal airway disease (elevated $\mathrm{C}_{\mathrm{ALV}}$, air trapping on a high resolution $\mathrm{CT}$ scan or abnormal lung clearance index), a trial of at least three months of fine particle ICS or oral prednisolone should be considered.

\section{The Symbicort Maintenance and Reliever Therapy regime}

This therapy regimen relies on the use of a single inhaler for budesonide and formoterol as regular therapy and for exacerbations (Symbicort Maintenance and Reliever Therapy, SMART regime). It has mainly been studied in adults with severe uncontrolled asthma and exacerbations in spite of regular ICS or ICS/LABA combination treatment [38]. In school-age children with asthma uncontrolled on ICS, use of budesonide/formoterol $80 / 4.5 \mathrm{mcg}$ combination once daily for maintenance plus additional inhalations of the same combination for symptom relief substantially reduced the frequency of asthma exacerbations, but had no significant effects on hospitalizations, asthma control days, need for rescue treatment and symptom free-days, when compared to identical dose of budesonide/formoterol for maintenance plus terbutaline for rescue, or fourfoldhigher maintenance dose of budesonide $(320 \mathrm{mcg}$ once daily) plus terbutaline for rescue [39]. As far as safety is concerned, the optimal SMART daily dose for children with severe asthma has not been studied.

SMART approach is a promising strategy for paediatric asthma management, but needs to be confirmed in future studies [40]. It is worth considering especially in children with severe, therapy-resistant asthma with severe exacerbations as a major concern. A very simple regime such as SMART may be useful in poorly adherent asthmatics, but again further trials are needed to confirm this.

\section{Low-dose theophylline}

Theophylline has been rediscovered as a potentially beneficial agent in asthma [41]. Low-dose theophylline, aiming at blood levels below the conventional therapeutic range (5-10 instead of $10-20 \mathrm{~mol} / \mathrm{L}$ ) has a number of immunomodulatory properties. Theophylline has been proved to inhibit the late phase response to aeroallergen challenge [42], accelerate neutrophil apoptosis [43], prevent down-regulation of the $\beta$-receptor by $\beta-2$ agonists [44], and down-regulate inflammatory gene expression via effects on histone acetylases (HATs) and histone deacetylases (HDACs) [45]. Both this proteins are abnormal in asthma, and this is reversed by glucocorticoids as well as theophylline, leading to a reduction in many inflammatory proteins. Clinical effects of adding theophylline to ICS have been generally small, both in adults [46] and in children [47].

Since asthmatic children may react different from adults, a therapeutic attempt with low-dose theophylline for some months should be tried in individual children with severe therapy-resistant asthma, especially in those with predominant neutrophilic airway inflammation. However, these are very rare.

\section{Intramuscular triamcinolone}

Depot triamcinolone has the same class effects as prednisolone, with the additional risk of subcutaneous atrophy at the injection site, but may be better in the control of asthma because adherence to treatment ceases to be an issue if the injections are given [48]. A single dose of triamcinolone has been suggested to be used as a therapeutic trial of steroid resistance [3]. Since acquired steroid resistance is a spectrum, it could be argued that multiple injections of triamcinolone may be more appropriate than a single dose. Two small paediatric studies suggest that triamcinolone may improve symptoms and reduce airway inflammation in children with severe asthma $[49,50]$.

The exact place of depot triamcinolone as a treatment for severe therapy-resistant pediatric asthma is not clear. It would seem reasonable to offer a trial for a finite period to those children in whom poor adherence to OCS is suspected.

\section{Experimental therapies}

Due to the severe side-effects of OCS when administered over long periods at high doses, many drugs have been assessed in the search for a possible corticosteroid-sparing agent [51]. At present, there are no agreed guidelines on the selection of suitable patients and on the order in which these therapies should be tried. However, it would seem irrational to give more and more powerful anti-inflammatory medications to symptomatic children in whom no evidence of inflammation can be detected (discordant phenotype). Irrespective of the therapy chosen, the use of any of the following drugs should be preceded by open discussion with the child and family to achieve awareness of safety aspects and monitoring. The characteristics of the studies with experimental drugs used in adults and children with severe asthma are shown in table 1.

\section{Macrolide antibiotics}

Macrolides have proven immunomodulatory activities in addition to their antibacterial effects $[52,53]$. In adults, macrolides have been shown to reduce neutrophilic inflammation [54], bronchial responsiveness [55] and airway oedema [56], and to increase the steroid responsiveness of peripheral blood lymphocytes [57]. Some of these anti-inflammatory effects have been demonstrated also in children [58-60]. Macrolides have been formerly used with variable results in diseases where neutrophilic inflammation is predominant, such as diffuse panbronchiolitis $[61,62]$, cystic fibrosis [63$65]$ and non-cystic fibrosis bronchiectasis [66, 67]. Macrolides have the advantage of probably being the safest 'add-on' therapy.

Troleandomycin was initially proposed as a steroid-sparing agent in adults [68-70] and chil- 
Table 1. - Characteristics of the studies conducted with experimental drugs in asthma

\begin{tabular}{|c|c|c|c|c|}
\hline Medication & Population & Study & $\mathbf{N}^{\circ}$ patients & Effect \\
\hline \multirow[t]{2}{*}{ Macrolides } & adults & DB RPC & $\mathrm{n}=657$ & $\begin{array}{l}\text { lung function improvement, } 78,79 \text { clinical } \\
\text { improvement, } 79,80 \text { no efficacy } 81\end{array}$ \\
\hline & children & DB RPC & $\mathrm{n}=55$ & no efficacy 82 \\
\hline \multirow[t]{2}{*}{ Cyclosporin } & adults & $\mathrm{RPC}$ & $\mathrm{n}=106$ & steroid sparing 89 \\
\hline & children & $\mathrm{CR}$ & $\mathrm{n}=5$ & steroid sparing 90 \\
\hline \multirow[t]{2}{*}{ Methotrexate } & adults & $\mathrm{RPC}$ & $\mathrm{n}=185$ & steroid sparing, no lung function improvement ${ }^{92}$ \\
\hline & children & $\mathrm{CR}$ & $\mathrm{n}=20$ & $\begin{array}{l}\text { steroid sparing; } 93,94,95 \text { clinical improvement; } 93 \\
\text { pulmonary function improvement } 94\end{array}$ \\
\hline \multirow[t]{2}{*}{ Azathioprine } & adults & RPC & $\mathrm{n}=23$ & no efficacy 96 \\
\hline & children & l & l & / \\
\hline \multirow[t]{2}{*}{ Gold salts } & adults & DB RPC & $\mathrm{n}=376$ & steroid sparing (small effect) ${ }^{97}$ \\
\hline & children & l & l & / \\
\hline \multirow[t]{3}{*}{ Immunoglobulins } & adults & l & l & / \\
\hline & mixed & DB RPC & $\mathrm{n}=78$ & steroid sparing, ${ }^{98}$ no efficacy, ${ }^{99}$ severe side effects 99 \\
\hline & children & OL; DB RPC & $\mathrm{n}=30 ; \mathrm{n}=31$ & $\begin{array}{l}\text { steroid sparing, } 100,101,102 \text { pulmonary function } \\
\text { improvement; } 100 \text { no efficacy } 103\end{array}$ \\
\hline \multirow[t]{2}{*}{ Antifungal agents } & adults & DB RPC & $\mathrm{n}=58$ & quality of life improvement 110 \\
\hline & children & $\mathrm{CR}$ & $\mathrm{n}=1$ & clinical improvement ${ }^{111}$ \\
\hline \multirow[t]{2}{*}{ Subcutaneous terbutaline } & adults & $\mathrm{CR}$ & $\mathrm{n}=31$ & $\begin{array}{l}\text { steroid sparing, reduced hospital admission, } \\
\text { pulmonary function improvement } 113,114\end{array}$ \\
\hline & children & $\mathrm{CR}$ & $\mathrm{n}=19$ & steroid sparing, clinical improvement 115,116 \\
\hline
\end{tabular}

DB: double blind; RPC: randomised placebo controlled; OL: open label; CR: case report.

dren [71] with severe asthma, but it is no longer recommended for asthma treatment [72]. Indeed, a randomised controlled trial showed that benefits on asthma control were related to the reduction of steroid catabolism [73], mainly methyl prednisolone, with an increase in side-effects in face of an apparently reassuring dose reduction [74-76]. It is likely that any macrolides may increase the halflife of corticosteroids [77].

The possible role of atypical respiratory infections in asthma was another factor which led to explorations of the potential effects of macrolides in asthmatics. Clarithromycin [78], roxithromycin [79] and telithromycin [80] have been studied with promising results in asthmatic adults with respiratory infection due to Mycoplasma pneumoniae or Chlamydia pneumoniae. A recent trial in adults with asthma suboptimally controlled by low-dose inhaled corticosteroids showed that adding clarithromycin to fluticasone did not further improve asthma control, although there was an improvement in airway hyperresponsiveness [81]. Azithromycin and montelukast were also compared as add-on therapies for children symptomatic despite ICS and LABA, but only a minority of referred children could be randomised, because most of the rest either did not have asthma at all, or were not taking their treatment [82]. Despite intrinsic limitations of this study, the authors consid- ered that even if the recruitment target had been met, a benefit would have been unlikely. The difficulty in recruitment underscores the fact that many so-called severe asthmatics merely need to get the basics right. A recent open-label study in asthmatic children presenting with an acute exacerbation showed that a 3-week course of clarithromycin in addition to regular treatment was associated with an increase in the number of symptom-free days, reduction in the number of days with loss of control, and decrease in the duration of the initial asthma exacerbation [83] The results of previous studies with macrolides in asthma are encouraging, but prospective controlled trials in patients with severe asthma are needed to confirm initial observations of efficacy [84].

The recent finding of a rich bacterial flora in the lower airways [85] and the association of airway microbiota with the degree of airway hyperresponsiveness among patients with suboptimally controlled asthma [86] suggest that the antibacterial role of macrolides could overweight the immunological effects, or at least should be used cautiously. This also supports the need for further studies to examine the potential contribution of airway microbiota in asthma pathogenesis.

As macrolides are safer than cytotoxic agents, it seems reasonable to propose using a therapeutic trial of macrolide antibiotics particularly in chil- 
dren with severe therapy-resistant asthma who have predominantly neutrophilic airway inflammation. Possible side effects of macrolide treatment should be taken into account, the most important of these being gastrointestinal upset. Development of macrolide resistance among respiratory pathogens is very common during longterm macrolide treatment [87], and we caution about inducing macrolide resistance with this approach [88].

\section{Cyclosporin}

There are three trials of cyclosporin in adults with steroid-dependent asthma [89] and the results are questionable. Paediatric data is anecdotal [90]. A trial of cyclosporine could be considered in children with persistent eosinophilic airway inflammation despite OCS therapy or requirement of unacceptable high levels of OCS to control asthma. Whether in the future nebulized cyclosporine may be beneficial with fewer side-effects is an important unanswered question [91].

\section{Cytotoxics}

Methotrexate and azathioprine have been used in severe corticosteroid-dependent asthma.

\section{Methotrexate}

Studies in asthmatic adults showed a small benefit in reducing the OCS dose, but the appearance of significant side-effects [92]. Side-effects were uncommon in three pilot trials performed in children with steroid-dependent asthma [93-95], thus suggesting a trial of methotrexate should be considered in children with steroid-resistant airway inflammation and in those requiring highdose OCS to maintain control of asthma.

\section{Azathioprine}

Data on azathioprine in asthma is extremely poor and limited to adults [96]. There is therefore no evidence for recommending such treatment in children with asthma.

\section{Gold salts}

Studies in asthmatic adults are limited and the results of limited clinical significance [97]. Given the lack of published paediatric data and the risk of serious adverse events, this therapy cannot be recommended in children with severe therapy-resistant asthma.

\section{Immunoglobulins}

Both observational and randomized trials have been conduced with intravenous immunoglobulins in adults [98, 99] and children [100-103] with severe asthma with conflicting results. Doses and frequency of administration of immunoglobulins have been variable. Given the lack of adequately powered paediatric studies and standardised treatment, a trial with intravenous immunoglobulins should probably be confined to asthmatic children who are OCS dependent. The safety profile is better than with methotrexate, although the fiscal cost, and inconvenience to the patients, is not small.

\section{Anti-fungal therapy}

The concept of severe asthma with fungal sensitisation (SAFS) is becoming established [104]. There is considerable evidence that fungal sensitisation and exposure are associated with increased morbidity and severity of asthma [105-107]. If a diagnosis of SAFS is suspected, sensitisation should be tested both with skin prick tests (SPT) and specific Radioallergen Absorbent Tests (RAST), since concordance between the two tests is highly variable $[108,109]$. SAFS is diagnosed in a patient of any age with evidence of sensitisation on either SPT or RAST to at least one fungus (table 2). The scientific evidence is limited to a double-blind, placebo-controlled clinical trial in adults [110] and a single case report in children [111].

Children with possible SAFS, who are not controlled after eliminating as far as possible any moulds in the environment, may be candidates for a trial of oral itraconazole or even voriconazole if symptoms persist. The interaction between ICS and itraconazole leading to Cushing's syndrome should be kept in mind [112].

\section{Subcutaneus terbutaline infusion}

Continuous subcutaneus terbutaline infusion (CSTI) is hypothesised to stimulate a discrete set of $\beta$-receptors not accessible by the inhaled route. There is limited literature in adults $[113,114]$ and children $[115,116]$. No randomized controlled trials exist for the use of CSTI, which therefore remains off-license for the treatment of asthma. A recent review found that CSTI led to improved outcomes in approximately $75 \%$ of patients, which included rises in lowest daily peak expiratory flow rate, diminution in diurnal variation, reduction in other medication requirements, and subjective opinion of symptoms [117].

It may be reasonable to trial this regimen in selected children in whom airway inflammation has been clearly demonstrated and in whom there is a marked peak flow variability despite highdose ICS and concomitant therapy with additional drugs. Treatment should be commenced under close supervision, using a double-blind protocol. Placebo effect is high and the benefits of a favourable hospital environment cannot be excluded, so we are now using an out-patient protocol with eight clinic visits over a four week period. Additional problems may be due to local reactions [118], risk of hypokalaemia [119] and

Table 2. - Fungi implicated in SAFS

Aspergillus fumigatus

Alternaria alternate

Cladosporium herbarum

Penicillium chrysogenum

Candida albicans

Trichophyton mentagrophytes

Botrytis cinerea 
skeletal myositis with elevation of creatine kinase [120].

\section{Treatment of the exacerbating phenotype}

There is evidence that poor baseline control and exacerbations may overlap, but are not the same [121]. The first is characterised by chronic symptoms of airway obstruction and marked diurnal variability of the peak flow despite high-dose ICS and other controllers; the latter are usually virally mediated and are characterized by a steep decline in peak flow without increased diurnal variability. Persistently poor baseline control and previous severe exacerbations are both predictive of future acute exacerbations [122-125]. However, good baseline control does not prevent the child having exacerbations, and no study has succeeded in completely abolishing exacerbations by any strategy [126].

There is a clear interaction between viral respiratory infections and allergens in asthma. One study showed that the combination of viral upper respiratory tract infection, allergen sensitisation, and high level of allergen exposure in the child's home was strongly predictive of an exacerbation severe enough to merit admission to hospital [127]. Although no study has convincingly shown that reducing allergen burden reduces exacerbations in children with severe, therapy-resistant asthma, such an approach, described in more detail elsewhere [128], would seem reasonable.

Management should include every effort to identify allergic triggers and minimise allergen exposure, and to optimise asthma control and lung function with lowest possible dose of ICS, in order to reduce airway inflammation in between exacerbations. Low-dose ICS are able to reduce the risk of exacerbations in children with mild-to moderate asthma $[124,125]$. There is some evidence that the use of oral LTRA [129], or very high dose ICS $[130,131]$, at the time of exacerbation, may reduce the need for OCS in exacerbations. There is no study exploring the effects of high-dose ICS and LTRA together, but this combination could be considered, if appropriate. There is no evidence that the use of ever-increasing doses of ICS between exacerbations in children with good baseline control is effective. There is also no evidence suggesting that, in the child with repeated exacerbations mandating oral prednisolone bursts, the prescription of daily or alternate low-dose OCS will prevent these exacerbations. These strategies are therefore not recommended.

Finally, the rare child who has catastrophic drops in lung function over a few minutes on the background of apparent excellent control (Type 2 brittle asthma) may on an anecdotal basis benefit from being given injectable adrenaline (for example, Epipen ${ }^{\mathrm{TM}}$ ) for emergency treatment of these deteriorations, enabling very rapid administration of a sympathomimetic ( $\alpha$ and $\beta$ ) intramuscularly, while more selective inhaled treatment is being prepared. Food allergy is common in this group and should be actively sought as part of the treatment programme [132, 133].

\section{Monitoring therapy}

In the context of adult and less severe paediatric asthma, the use of FENO has not been shown to improve daily asthma control or reduce the daily dose of ICS [134]. However, some trials using tools such as induced sputum or bronchial responsiveness to monitor asthma suggested that using inflammometry may lead to better control without the need for bigger ICS doses [135, 136]. From adult data, it would appear that the greatest benefit of inflammometry is in those with more severe disease [137]. In children, FENO has been used to predict successful reduction in ICS dose [138] and relapse after stopping ICS altogether [139]. The only study which has tested this in children with severe, therapy-resistant asthma showed only trends in benefit for inflammometry [140]. One problem may be that sputum phenotypes in children may be less stable than in adults [141]. A recent study in school age children with asthma showed that both exhaled breath condensate IL-5 level and asthma control score were significant predictors of asthma exacerbation, thus opening up the possibility of assessing the potential of such parameters to titrate asthma treatment in future studies [142]. More work is needed to determine how best to monitor treatment to minimise side-effects and maximise benefits in this challenging group of patients.

\section{Conclusions and future directions}

There is a limited evidence for the various treatment options for children with severe, therapy resistant asthma. Therefore, before employing any of them, every effort must be made to confirm the diagnosis, and to ensure that the basic management is right. Several subtypes of severe asthma are now recognized $[143,144]$, and in the future it will be necessary to find biomarkers that may predict responses to specific, individualised therapies [145]. It will be also important to ensure that children are part of clinical trials in severe, therapy-resistant asthma, allowing new promising therapies, such as new anti-cholinergic agents [146], anti-IL5 [147, 148], anti-IL13 [149], and even bronchial thermoplasty $[150,151]$ to be trialled in suitable children. In this context, the need for international collaboration with standard assessments of the children across Europe, is strongly warranted $[152,153]$.

Acknowlegments: The authors thank Luigi Pietroni, Salesi Children's Hospital, for his outstanding support in the laboratory evaluation of children with severe asthma, and the severe asthma team at the Royal Brompton Hospital for their superb work. AB was supported by the NIHR Respiratory Disease Biomedical Research Unit at the Royal Brompton and Harefield NHS Foundation Trust and Imperial College of London. 


\section{References}

1. Hedlin G, Bush A, Lødrup Carlsen K, et al on behalf of the PSACI (Problematic Severe Asthma in Childhood Initiative) group. Problematic severe asthma in children: not one problem but many. A GA2LEN initiative. Eur Respir J 2010; 36: 196-201.

2. Lødrup Carlsen K, Hedlin G, Bush A, et al on behalf of the PSACI (Problematic Severe Asthma in Childhood Initiative) group. Assessment of problematic severe asthma in children. Eur Respir J 2011; 37: 432-440.

3. Hedlin G, de Benedictis FM, Bush A. Problematic severe asthma. Eur Respir Monogr 2012; 56: 22-39.

4. Sweeney J, Brightling CE, Menzies-Gow A, et al Clinical management and outcome of refractory asthma in the UK from the British Thoracic Society Difficult Asthma Registry. Thorax 2012; 67: 754-6.

5. Bush A, Pedersen S, Hedlin G, et al on behalf of the PSACI (Problematic Severe Asthma in Childhood Initiative) group. Pharmacological treatment of severe, therapy-resistant asthma in children: what can we learn from where? Eur Respir J 2011; 38: 947-958.

6. Zhang L, Axelsson I, Chung M, Lau J. Dose response of inhaled corticosteroids in children with persistent asthma: A systematic review. Pediatrics 2011; 127: 129-138.

7. Lemanske RF Jr, Mauger DT, Sorkness CA, et al. Childhood Asthma Research and Education (CARE) Network of the National Heart, Lung, and Blood Institute. Step-up therapy for children with uncontrolled asthma receiving inhaled corticosteroids. $N$ Engl J Med 2010; 362: 975-985.

8. Nimmagadda SR, Szefler SJ, Spahn JD, Surs W, Leung DYM. Allergen exposure decreases glucocorticoid receptor binding affinity and steroid responsiveness in atopic asthmatics. Am J Respir Crit Care Med 1997; 155: 87-93.

9. Brutsche MH, Brutsche IC, Munawar M, et al. Comparison of pharmacokinetics and systemic effects of inhaled fluticasone propionate in patients with asthma and healthy volunteers: a randomised crossover study. Lancet 2000; 356: 556-561.

10. Adams NP, Bestall JC, Jones P, Lasserson TJ, Griffiths B, Cates CJ. Fluticasone at different doses for chronic asthma in adults and children. Cochrane Database Syst Rev 2008; (8): CD003534.

11. Van Staa TP, Cooper C, Leufkens HG, et al. Children and the risk of fractures caused by oral corticosteroids. J Bone Miner Res 2003; 18: 913-918.

12. Allen DB. Effects of inhaled steroids on growth, bone metabolism, and adrenal function. Adv Pediatr 2006; 53: 101-110.

13. de Benedictis FM, Bush A. Corticosteroids in respiratory diseases in children. Am J Respir Crit Care Med 2012; 185: 12-23.

14. Milgrom, H, Berger W, Nayak A, et al. Treatment of Childhood Asthma with Anti-Immunoglobulin E Antibody (Omalizumab). Pediatrics 2001; 108: 6-45.

15. Lemanske R, Nayak A, McAlary M, Everhard F, FowlerTaylor A, Gupta N. Omalizumab improves asthma-related quality of life in children with allergic asthma. Pediatrics 2002; 110: e55-59.

16. Lanier B, Bridges T, Kulus M, et al. Omalizumab for the treatment of exacerbations in children with inadequately controlled allergic (IgE-mediated) asthma. $J \mathrm{Al}$ lergy Clinical Immunol 2009; 124: 1210-1216.

17. Busse WW, Morgan WJ, Gergen PJ, et al. Randomized trial of omalizumab (anti-IgE) for asthma in inner-city children. N Engl J Med 2011; 364: 1005-1015.

18. Brodlie M, McKean MC, Moss, S, Spencer DA. The oral corticosteroid-sparing effect of omalizumab in children with severe asthma. Arch Dis Child 2012; 97 : 604-9.
19. Pavord ID, Bush A. Anti-IgE asthma in inner-city children. N Engl J Med 2011; 364: 2556-2558.

20. Storms W, Bowdish MS, Farrar JR. Omalizumab and asthma control in patients with moderate-to-severe allergic asthma: a 6-year pragmatic data review. Allergy Asthma Proc 2012; 33: 172-177.

21. Rodrigo GJ, Neffen H, Castro-Rodriguez JA. Efficacy and safety of subcutaneous omalizumab vs placebo as add-on therapy to corticosteroids for children and adults with asthma: a systematic review. Chest 2011; 139: 28-35.

22. Bush A, Lenney W, Spencer D, et al. Not NICE: a better way forward? Arch Dis Child 2011; 96: 907-908.

23. Djukanović R, Wilson SJ, Kraft M, et al. Effects of treatment with anti-immunoglobulin $\mathrm{E}$ antibody omalizumab on airway inflammation in allergic asthma. Am J Respir Crit Care Med 2004; 170: 583-593.

24. Silkoff PE, Romero FA, Gupta N, Yownley RG, Milgrom $\mathrm{H}$. Exhaled nitric oxide in children with asthma receiving xolair (omalizumab) , a monoclonal anti-immunoglobulin E antibody. Pediatrics 2004; 113: e308-312.

25. Busse WW, Gergen PJ, Calatroni A. Anti-IgE asthma in inner-city children. N Engl J Med 2011; 364: 25562558.

26. Wahn U, Martin C, Freeman P, Blogg M, Jimenez P. Relationship between pretreatment specific $\operatorname{IgE}$ and the response to omalizumab therapy. Allergy 2009; 64: 1780-1787.

27. Oba Y, Salzman GA. Cost-effectiveness analysis of omalizumab in adults and adolescents with moderateto-severe allergic asthma. J Allergy Clin Immunol 2004; 114: 265-269.

28. Kraft M, Djukanovic R, Wilson S, Holgate ST, Martin RJ. Alveolar tissue inflammation in asthma. Am J Respir Crit Care Med 1996; 154: 1505-1510.

29. Sutherland ER, Martin RJ, Bowler RP, Zhang Y, Rex MD, Kraft M. Physiologic correlates of distal lung inflammation in asthma. J Allergy Clin Immunol 2004; 113: 1046-1050.

30. Kraft M, Martin RJ, Wilson S, Djukanovic R, Holgate ST. Lymphocyte and eosinophil influx into alveolar tissue in nocturnal asthma. Am J Respir Crit Care Med 1999; 159: 228-234.

31. Tsoukias NM, George SC. A two-compartment model of pulmonary nitric oxide exchange dynamics. J Appl Physiol 1998; 85: 653-666.

32. Tsoukias NM, Shin HW, Wilson AF, George SC. A single-breath technique with variable flow rate to characterize nitric oxide exchange dynamics in the lungs. $J$ Appl Physiol 2001; 91: 477-487.

33. Piacentini GL, Bodini A, Costella S, et al. Exhaled nitric oxide and sputum eosinophil markers of inflammation in asthmatic children. Eur Respir J 1999; 13: 1386-1390.

34. Nair P, Kjarsgaard M, Armstrong S, et al. Nitric oxide in exhaled breath is poorly correlated to sputum eosinophils in patients with prednisone-dependent asthma. J Allergy Clin Immunol 2010; 126: 404-406.

35. Paraskakis E, Brindicci C, Fleming L, et al. Measurement of bronchial and alveolar nitric oxide production in normal children and children with asthma. Am J Respir Crit Care Med 2006; 174: 260-267.

36. Cohen J, Douma WR, ten Hacken NH, Vonk JM, Oudkerk M, Postma DS. Ciclesonide improves measures of small airway involvement in asthma. Eur Respir $J$ 2008; 31: 1213-1220

37. Cohen J, Postma DS, Douma WR, et al. Particle size matters: diagnostics and treatment of small airways involvement in asthma. Eur Respir J 2011; 37: 532-540.

38. Cates CJ, Lasserson TJ. Combination formoterol and budesonide as maintenance and reliever therapy versus inhaled steroid maintenance for chronic asthma in adults and children. Cochrane Database Syst Rev 2009; (2): CD007313. 
39. Bisgaard H, Le Roux P, Bjamer D, Dymek A, Vermeulen JH, Hultquist C. Budesonide/formoterol maintenance plus reliever therapy: a new strategy in pediatric asthma. Chest 2006; 130: 1733-1743.

40. Chapman KR, Barnes NC, Greening AP, Jones PW, Pedersen S. Single maintenance and reliever therapy (SMART) of asthma: a critical appraisal. Thorax 2010; 65: 747-752.

41. Kidney J, Dominguez M, Taylor PM, Rose M, Chung $\mathrm{KF}$, Barnes PJ. Immunomodulation by theophylline in asthma. Demonstration by withdrawal of therapy. Am J Respir Crit Care Med 1995; 151: 1907-1914.

42. Sullivan PJ, Bekir S, Jaffar Z, Page CP, Jeffery PK, Costello J. The effects of low-dose theophylline on the bronchial wall infiltrate after allergen challenge. Lancet 1993; 343: 1006-1008.

43. Yasui K, Hu B, Nakazawa T, Agematsu K, Komiyama A. Theophylline accelerates human granulocyte apoptosis not via phosphodiesterase inhibition. J Clin Invest 1997; 100: 1677-1684.

44. Derks MG, Koopmans RP, Oosterhoff E, Van Boxtel CJ. Prevention by theophylline of beta-2-receptor down regulation in healthy subjects. Eur J Drug Metab Pharmacokinet 2000; 25: 179-188.

45. Cosío BG, Mann B, Ito K, et al. Histone acetylase and deacetylase activity in alveolar macrophages and blood mononocytes in asthma. Am J Respir Crit Care Med 2004; 170: 141-147.

46. American Lung Association Asthma Clinical Research Centers. Clinical trial of low-dose theophylline and montelukast in patients with poorly controlled asthma. Am J Respir Crit Care Med 2007; 175: 235-242.

47. Seddon P, Bara A, Ducharme FM, Lasserson TJ. Oral xanthines as maintenance treatment for asthma in children. Cochrane Database Syst Rev 2006; (1): CD002885.

48. Willey RF, Fergusson RJ, Godden DJ, Crompton GK, Grant IW. Comparison of oral prednisolone and intramuscular depot triamcinolone in patients with severe chronic asthma. Thorax 1984; 39: 340-344.

49. Panickar JR, Kenia P, Silverman M, Grigg J. Intramuscular triamcinolone for difficult asthma. Pediatr Pulmonol 2005; 39: 421-425.

50. Panickar JR, Bhatnagar N, Grigg J. Exhaled nitric oxide after a single dose of intramuscular triamcinolone in children with difficult to control asthma. Pediatr Pulmonol 2007; 42: 573-578.

51. Domingo C, Moreno A, Mirapeix R. Rationale for the use of immunomodulatory therapies in the Global Initiative for Asthma (GINA) step V asthma other than oral glucocorticoids. Int Med J 2011; 41: 525-536.

52. Jaffe A, Bush A. Anti-inflammatory effects of macrolides in lung disease. Pediatr Pulmonol 2001; 31: 464-473.

53. Bush A, Rubin BK. Macrolides as biologic response modifiers in cystic fibrosis and bronchiectasis. Sem Resp Crit Care Med 2003; 24: 737-747.

54. Simpson JL, Powell H, Boyle MJ, Scott RJ, Gibson PG. Clarithromycin targets neutrophilic airway inflammation in refractory asthma. Am J Respir Crit Care Med 2008; 177: 148-155.

55. Kostadima E, Tsiodras S, Alexopoulos EI, et al. Clarithromycin reduces the severity of bronchial hyper-responsiveness in patients with asthma. Eur Respir $J$ 2004; 23: 714-717.

56. Chu HW, Kraft M, Rex MD, Martin RJ. Evaluation of blood vessels and edema in the airways of asthma patients: regulation with clarithromycin treatment. Chest 2001; 120: 416-422.

57. Spahn JD, Fost DA, Covar R, et al. Clarithromycin potentiates glucocorticoid responsiveness in patients with asthma: results of a pilot study. Ann Allergy Asthma Immunol 2001; 87: 501-505.
58. Piacentini GL, Peroni DG, Bodini A, et al. Azithromycin reduces bronchial hyperresponsiveness and neutrophilic airway inflammation in asthmatic children: a preliminary report. Allergy Asthma Proc 2007; 28: 194-198.

59. Fonseca-Aten M, Okada PJ, Bowlware KL, et al. Effect of clarithromycin on cytokines and chemokines in children with an acute exacerbation of recurrent wheezing: a double-blind, randomized, placebo-controlled trial. Ann Allergy Asthma Immunol 2006; 97: 457-463.

60. Shimizu T, Kato M, Mochizuki H, Tokuyama K, Morikawa A, Kuroume T. Roxithromycin reduces the degree of bronchial hyperresponsiveness in children with asthma. Chest 1994; 106: 458-461.

61. Kudoh S, Azuma A, Yamamoto M, Izumi T, Ando M. Improvement in survival of patients with diffuse panbronchiolitis treated with low dose erythromycin. Am J Respir Crit Care Med 1998; 157: 1829-1832.

62. Kadota J, Mukae H, Ishii H, et al. Long-term efficacy and safety of clarithromycin treatment in patients with diffuse panbronchiolitis. Respir Med 2003; 97: 844-850.

63. Wolter J, Seeney S, Bell S, et al. Effect of long term treatment with azithromycin on disease parameters in cystic fibrosis: a randomised controlled trial. Thorax 2002; 57: 212-216.

64. Equi A, Balfour-Lynn I, Bush A, Rosenthal M. Long term azithromycin in children with cystic fibrosis: a randomized, placebo-controlled crossover trial. Lancet 2002; 360: 978-984.

65. Clement A, Tamalet A, Leroux E, Ravilly S, Fauroux $B$, Jais JP. Long term effects of azithromycin in patients with cystic fibrosis: A double blind, placebo controlled trial. Thorax 2006; 61: 895-902.

66. Koh YY, Lee MH, Sun YH, Sung KW, Chae JH. Effect of roxithromycin on airway responsiveness in children with bronchiectasis: a double-blind, placebo-controlled study. Eur Respir J 1997; 10: 994-999.

67. Cymbala AA, Edmonds LC, Bauer MA, et al. The disease-modifying effects of twice-weekly oral azithromycin in patients with bronchiectasis. Treat Respir Med 2005; 4: 117-122.

68. Zeiger RS, Schatz M, Sperling W, Simon RA, Stevenson DD. Efficacy of troleandomycin in outpatients with severe, corticosteroid-dependent asthma. J Allergy Clin Immunol 1980; 66: 438-446.

69. Kamada AK, Hill MR, Iklé DN, Brenner AM, Szefler SJ. Efficacy and safety of low-dose troleandomycin therapy in children with severe, steroid-requiring asthma. J Allergy Clin Immunol 1993; 91: 873-882.

70. Siracusa A, Brugnami G, Fiordi T, Areni S, Severini C, Marabini A. Troleandomycin in the treatment of difficult asthma. J Allergy Clin Immunol 1993; 92: 677-682.

71. Eitches RW, Rachelefsky GS, Katz RM, Mendoza GR, Siegel SC. Methylprednisolone and troleandomycin in treatment of steroid-dependent asthmatic children. Am J Dis Child 1985; 139: 264-268.

72. Evans DJ, Cullinan P, Geddes DM. Troleandomycin as an oral corticosteroid steroid sparing agent in stable asthma. Cochrane Database Syst Rev 2001; (2): CD002987.

73. Nelson HS, Hamilos DL, Corsello PR, Levesque NV, Buchmeier AD, Bucher BL. A double-blind study of troleandomycin and methylprednisolone in asthmatic subjects who require daily corticosteroids. Am Rev Respir Dis 1993; 147: 398-404.

74. Flotte TR, Loughlin GM. Benefits and complications of troleandomycin (TAO) in young children with steroiddependent asthma. Pediatr Pulmonol 1991; 10: 178-182.

75. Fost DA, Leung DY, Martin RJ, Brown EE, Szefler SJ, Spahn JD. Inhibition of methylprednisolone elimination in the presence of clarithromycin therapy. $J$ Allergy Clin Immunol 1999; 103: 1031-1035.

76. Ball BD, Hill MR, Brenner M, Sanks R, Szefler SJ. Effect of low-dose troleandomycin on glucocorticoid phar- 
macokinetics and airway hyperresponsiveness in severely asthmatic children. Ann Allergy 1990; 65: 37-45.

77. Fost DA, Leung DY, Martin RJ, et al. Inhibition of methyilprednisolone elimination in the presence of clarithromycin therapy. J Allergy Clin Immunol 1999; 103: 1031-1035.

78. Kraft M, Cassell GH, Pak J, Martin RJ. Mycoplasma pneumoniae and Chlamydia pneumoniae in asthma: effect of clarithromycin. Chest 2002; 121: 1782-1788.

79. Black PN, Blasi F, Jenkins CR, et al. Trial of roxithromycin in subjects with asthma and serological evidence of infection with Chlamydia pneumoniae. Am J Respir Crit Care Med 2001; 164: 536-541.

80. Johnston SL, Blasi F, Black PN, Martin RJ, Farrell DJ, Nieman RB, TELICAST Investigators. The effect of telithromycin in acute exacerbations of asthma. $N$ Engl J Med 2006; 354: 1589-1600.

81. Sutherland ER, Kings TS, Icitovic N, et al. A trial of clarithromycin for the treatment of suboptimally controlled asthma. J Allergy Clin Immunol 2010; 126: 747-753.

82. Strunk RC, Bacharier LB, Phillips BR, et al; CARE Network. Azithromycin or montelukast as inhaled corticosteroid-sparing agents in moderate-to-severe childhood asthma study. J Allergy Clin Immunol 2008; 122: 1138-1144.

83. Koutsoubari I, Papaevangelou V, Konstantinou GN, et al. Effect of clarithromycin on acute asthma exacerbation in children: an open study. Pediatr Allergy Immunol 2012; 23: 385-390.

84. Coeman M, van Durme Y, Bauters F, et al. Neomacrolides in the treatment of patients with severe asthma and/or bronchiectasis: a retrospective observational study. Ther Adv Respir Dis 2012; 5: 377-386.

85. Hilty M, Burke C, Pedro H, et al. Disordered microbial communities in asthmatic airways. PLoS One 2010; 5: e8578.

86. Huang YJ, Nelson CE, Brodie EL, et al. Airway microbiota and bronchial hyperresponsiveness in patients with suboptimally controlled asthma. J Allergy Clin Immunol 2011; 127: 372-381

87. Seppälä H, Klaukka T, Vuopio-Varkila J, et al. The effect of changes in the consumption of macrolide antibiotics on erythromycin resistance in group A streptococci in Finland. Finnish Study Group for Antimicrobial Resistance. N Engl J Med 1997; 337: 441-446.

88. Altenburg J, de Graff CS, van der Werf TS, Boersma WG. Immonumodulatory effects of macrolide antibiotics - part 2: advantages and disadvantages of long-term, lowdose macrolide therapy. Respiration 2011; 81: 75-87.

89. Evans DJ, Cullinan P, Geddes DM. Cyclosporin as an oral corticosteroid sparing agent in stable asthma. Cochrane Database Syst Rev 2001; (2): CD002993.

90. Coren ME, Rosenthal M, Bush A. The use of cyclosporin in corticosteroid dependent asthma. Arch Dis Child 1997; 77: 522-523.

91. Iacono AT, Johnson BA, Grgurich WF, et al. A randomized trial of inhaled cyclosporine in lung-transplant recipients. $N$ Engl J Med 2006; 354: 141-150.

92. Davies H, Olson L, Gibson P. Methotrexate as a steroid sparing agent for asthma in adults. Cochrane Database Syst Rev 2000; (2): CD000391.

93. Stempel DA, Lammert J, Mullarkey MF. Use of methotrexate in the treatment of steroid-dependent adolescent asthmatics. Ann Allergy 1991; 67: 346-348.

94. Guss S, Portnoy J. Methotrexate treatment of severe asthma in children. Pediatrics 1992; 89: 635-639.

95. Solé D, Costa-Carvalho BT, Soares FJ, Rullo VV, Naspitz CK. Methotrexate in the treatment of corticodependent asthmatic children. J Investig Allergol Clin Immunol 1996; 6: 126-130.

96. Dean T, Dewey A, Bara A, Lasserson TJ, Walters EH. Azathioprine as an oral corticosteroid sparing agent for asthma. Cochrane Database Syst Rev 2004; (1): CD003270.

97. Evans DJ, Cullinan P, Geddes DM. Gold as an oral corticosteroid sparing agent in stable asthma. Cochrane Database Syst Rev 2001; (2): CD002985.

98. Salmun LM, Barlan I, Wolf HM, et al. Effect of intravenous immunoglobulin on steroid consumption in patients with severe asthma: a double-blind, placebo-controlled, randomized trial. J Allergy Clin Immunol 1999; 103: 810-815

99. Kishiyama JL, Valacer D, Cunningham-Rundles C, et al. A multicenter, randomized, double-blind, placebocontrolled trial of high-dose intravenous immunoglobulin for oral corticosteroid-dependent asthma. Clin Immunol 1999; 91: 126-133.

100. Jakobsson T, Croner S, Kjellman NI, Pettersson A, Vassella C, Björkstén B. Slight steroid-sparing effect of intravenous immunoglobulin in children and adolescents with moderately severe bronchial asthma. Allergy 1994; 49: 413-420.

101. Mazer BD, Gelfand EW. An open-label study of highdose intravenous immunoglobulin in severe childhood asthma. J Allergy Clin Immunol 1991; 87: 976-983.

102. Niggemann B, Leupold W, Schuster A, et al. Prospective, double-blind, placebo-controlled, multicentre study on the effect of high-dose, intravenous immunoglobulin in children and adolescents with severe bronchial asthma. Clin Exp Allergy 1998; 28: 205-210.

103. Vrugt B, Wilson S, van Velzen E, et al. Effects of high dose intravenous immunoglobulin in two severe corticosteroid insensitive asthmatic patients. Thorax 1997; 52: 662-664.

104. Knutsen AP, Bush RK, Demain JG, et al. Fungi and allergic lower respiratory tract diseases. J Allergy Clin Immunol 2012; 129: 280-291.

105. O'Hallaren MT, Yunginger JW, Offord KP, et al. Exposure to aeroallergen as a possible precipitating factor in respiratory arrest in young patients with asthma. $N$ Engl J Med 1991; 324: 359-363.

106. Neukirch C, Henry C, Leynaert B, Liard R, Bousquet J, Neukirch F. Is sensitization to Alternaria alternate a risk factor for severe asthma? A population based study. $J$ Allergy Clin Immunol 1999; 103: 709-711.

107. Black PN, Udy AA, Brodie SM. Sensitivity to fungal allergens is a risk factor for life-threatening asthma. $A l$ lergy 2000; 55: 501-504.

108. O'Driscoll BR, Powell G, Chew F, et al. Comparison of skin prick tests with specific immunoglobulin $\mathrm{E}$ in the diagnosis of fungal sensitization in patients with severe asthma. Clin Exp Allergy 2009; 39: 1677-1683.

109. Frith J, Fleming L, Bossley C, et al. The complexities of defining atopy in severe childhood asthma. Clin Exp Allergy 2011; 41: 948-953.

110. Denning DW, O'Driscoll BR, Powell G, et al. Randomized controlled trial of oral antifungal sensitization. The fungal asthma sensitization trial (FAST) study. Am J Respir Crit Care Med 2009; 179: 11-18.

111. Vicencio AG, Muzumdar H, Tsirilakis K, Kessel A, Nandalike K, Goldman DL. Severe asthma with fungal sensitization in a child: Response to itraconazole therapy. Pediatrics 2010; 125: e1255-1258.

112. De Wachter E, Vanbesien J, De Schutter I, Malfroot A, De Schepper J. Rapidly developing Cushing syndrome in a 4-year-old patient during combined treatment with itraconazole and inhaled budesonide. Eur J Pediatr 2003; 162: 488-489.

113. Lewis LD, O'Driscoll BR, Hartley RB, Cochrane GM. An unusual local reaction to continuous subcutaneous infused terbutaline in unstable asthmatics. $\mathrm{Br} J \mathrm{Dis}$ Chest 1987; 81: 189-193.

114. O'Driscoll BR, Ruffles SP, Ayres JG, Cochrane GM. 
Long term treatment of severe asthma with subcutaneous terbutaline. Br J Dis Chest 1988; 82: 360-367.

115. Payne DNR, Balfour-Lynn IM, Biggart EA, Bush A, Rosenthal M. Subcutaneous terbutaline in children with chronic severe asthma. Pediatr Pulmonol 2002; 33: 356-361.

116. Brémont F, Moisan V, Dutau G. Continuous subcutaneous infusion of beta 2-agonists in infantile asthma. Pediatr Pulmonol 1992; 12: 81-83.

117. Jones GH, Scott SJ. Continuous infusions of terbutaline in asthma - a review. J Asthma 2011; 48: 753-756.

118. Lewis LD, O'Driscoll BR, Hartley RB, et al. An unusual local reaction to continuous subcutaneous infused terbutaline in unstable asthmatics. Br J Dis Chest 1987; 81: 189-193.

119. Smith SR, Kendall MJ. Potentiation of the adverse effects of intravenous terbutaline by oral theophylline. $\mathrm{Br}$ $J$ Clin Pharmacol 1986; 21: 451-453.

120. Sykes AP, Lawson N, Finnegan JA, Ayres JG. Creatine kinase activity in patients with brittle asthma treated with long term subcutaneous terbutaline. Thorax 1991; 46: $580-583$.

121. Reddel H, Ware S, Marks G, Salome C, Jenkins C, Woolcock A. Differences between asthma exacerbations and poor asthma control. Lancet 1999; 353: 364-369.

122. Covar RA, Szefler SJ, Zeiger RS, et al. Factors associated with asthma exacerbations during a long-term clinical trial of controller medications in children. J Allergy Clin Immunol 2008; 122: 741-747.

123. Haselkorn T, Zeiger RS, Chipps BE, et al. Recent asthma exacerbations predict future exacerbations in children with severe or difficult-to-treat asthma. J Allergy Clin Immunol 2009; 124: 921-927.

124. CAMP Study. Long-term effects of budesonide or nedocromil in children with asthma. The Childhood Asthma Management Program Research Group. N Engl J Med 2000; 343: 1054-1063.

125. Pauwels RA, Pedersen S, Busse WW, et al. Early intervention with budesonide in mild persistent asthma: a randomised, double-blind trial. Lancet 2003; 361: 1071-1076.

126. Pedersen S. From asthma severity to control: a shift in clinical practice. Prim Care Respir J 2010; 19: 3-9.

127. Murray CS, Poletti G, Kebadze T, et al. Study of modifiable risk factors for asthma exacerbations: virus infection and allergen exposure increase the risk of asthma hospital admissions in children. Thorax 2006; 61: 376-382.

128. Bracken MB, Fleming L, Hall $\mathrm{P}$, et al. The importance of nurse led home visits in the assessment of children with problematic asthma. Arch Dis Child 2009; 94: 780-784.

129. Robertson CF, Price D, Henry R, et al. Short-course montelukast for intermittent asthma in children: a randomized controlled trial. Am J Respir Crit Care Med 2007; 175: 323-329.

130. Ducharme FM, Lemire C, Noya FJ, et al. Preemptive use of high-dose fluticasone for virus-induced wheezing in young children. $N$ Engl J Med 2009; 360: 339-353.

131. Zeiger RS, Mauger D, Bacharier LB, et al., for the CARE Network of the National Heart, Lung, and Blood Institute. Daily or Intermittent budesonide in preschool children with recurrent wheezing. $N$ Eng J Med 2011; 365: 1990-2001.

132. Roberts G, Patel N, Levi-Schaffer F, et al. Food allergy as a risk factor for life-threatening asthma in childhood: a case-controlled study. J Allergy Clin Immunol 2003; 112: 168-174.

133. Simpson AB, Glutting J, Yousef E. Food allergy and asthma morbidity in children. Pediatr Pulm 2007; 42: 489-495.
134. Pedersen S, O'Byrne PM. Exhaled nitric oxide in guideline-based asthma management. Lancet 2008; 372: 1015-1017.

135. Sont JK, Willems LN, Bel EH, van Krieken JH, Vandenbroucke JP, Sterk PJ. Clinical control and histopathologic outcome of asthma when using airway hyperresponsiveness as an additional guide to longterm treatment. The AMPUL Study Group. Am J Respir Crit Care Med 1999; 159: 1043-1051.

136. Green RH, Brightling CE, McKenna S, et al. Asthma exacerbations and sputum eosinophil counts: a randomised controlled trial. Lancet 2002; 360: 1715-1721.

137. Jayaram L, Pizzichini MM, Cook RJ, et al. Determining asthma treatment by monitoring sputum cell counts: effect on exacerbations. Eur Respir $J$ 2006; 27: 483494.

138. Zacharasiewicz A, Wilson N, Lex C, et al. Clinical use of non-invasive measurements of airway inflammation in steroid reduction in children. Am J Respir Crit Care Med 2005; 177: 1077-1082.

139. Pijnenburg MW, Hofhuis W, Hop WC, De Jongste JC. Exhaled nitric oxide predicts asthma relapse in children with clinical asthma remission. Thorax 2005; 60: 215-218

140. Fleming L, Wilson N, Regamey N, Bush A. The use of non-Invasive markers of inflammation to guide management in children with severe asthma. Am J Respir Crit Care Med 2009; 179: A1305.

141. Bossley CJ, Fleming L, Gupta A, et al. Pediatric severe asthma is characterized by eosinophilia and remodeling without $\mathrm{T}(\mathrm{H}) 2$ cytokines. J Allergy Clin Immunol 2012; 129: 974-982.

142. Robroeks CM, van Vliet D, Jobsis Q, et al. Prediction of asthma exacerbations in children: results one-year prospective study. Clin Exp Allergy 20012; 42: 792-798.

143. Haldar P, Pavord ID, Shaw DE, et al. Cluster analysis and clinical asthma phenotypes. Am J Respir Crit Care Med 2008; 178: 218-224.

144. Bush A, Fleming L. Phenotypes of refractory/severe asthma. Paediatr Respir Rev 2011; 12: 177-181.

145. Barnes PJ. Severe asthma: advances in current management and future therapy. I Allergy Clin Immunol 2012; 129: 48-59.

146. Peters SP, Kunselman SJ, Icitovic N, et al, for the National Heart, Lung, and Blood Institute Asthma Clinical Research Network. Tiotropium bromide step-up therapy for adults with uncontrolled asthma. $N$ Engl J Med 2010; 363-1715-1726.

147. Haldar P, Brightling CE, Hargadon B, et al. Mepolizum$\mathrm{ab}$ and exacerbations of refractory eosinophilic asthma. N Engl J Med 2009; 360: 973-984.

148. Nair P, Pizzichini MM, Kjarsgaard M, et al. Mepolizum$\mathrm{ab}$ for prednisone-dependent asthma with sputum eosinophilia. N Engl J Med 2009; 360: 985-993.

149. Corren J, Lemanske RF, Hanania NA, et al. Lebrikizumab treatment in adults with asthma. $N$ Engl $\mathrm{J} \mathrm{Med}$ 2011; 365: 1088-1098.

150. Cox G, Thomson NC, Rubin AS, at al. Asthma control during the year after bronchial thermoplasty. $N$ Engl $J$ Med 2007; 356: 1327-1337.

151. Castro M, Rubin AS, Laviolette M, et al. Effectiveness and safety of bronchial thermoplasty in the treatment of severe asthma: a multicenter, randomized, double-blind, sham-controlled clinical trial. Am J Respir Crit Care Med 2010; 181: 116-124.

152. Bush A, Hedlin G, Calsen K-H, et al. Severe childhood asthma: a common international approach? Lancet 2008; 372: 1019-1021.

153. Bush A. Evidence-based medicines for children: important implications for new therapies at all ages. Eur Respir J 2006; 28: 1069-1072. 